\title{
Changes of Serum Concentrations of Brain-Derived Neurotrophic Factor (BDNF) during Treatment with Venlafaxine and Mirtazapine: Role of Medication and Response to Treatment
}

Authors

Affiliations

\author{
M. Deuschle ${ }^{1 *}$, M. Gilles ${ }^{1 *}$, B. Scharnholz ${ }^{1}$, F. Lederbogen ${ }^{1}$, U. E. Lang ${ }^{2}$, R. Hellweg ${ }^{2}$
}

${ }^{1}$ Faculty of Medicine Mannheim, Central Institute of Mental Health, University of Heidelberg, Germany ${ }^{2}$ Department of Psychiatry, Campus Mitte, Charité, Berlin, Germany

\author{
Key words \\ - brain-derived neurotrophic \\ factor (BDNF) \\ - depression \\ - remission \\ - antidepressant
}

\begin{abstract}
$\nabla$

Introduction: Depression, stress and antidepressant treatment have been found to modulate the expression of brain-derived neurotrophic factor (BDNF). Recent research suggests that serum BDNF concentration is reduced in depression and that antidepressant treatment leads to an increase in serum BDNF concentration.

Methods: We studied depressed patients receiving a randomized antidepressant treatment with either mirtazapine $(n=29)$ or venlafaxine $(n=27)$ for 28 days in a prospective design. Changes in the concentrations of serum neurotrophins in response to antidepressant treatment were assessed.
\end{abstract}

\section{Introduction}

$\nabla$

$\begin{array}{ll}\text { received } & 16.01 .2012 \\ \text { revised } & 06.06 .2012 \\ \text { accepted } & 11.07 .2012\end{array}$

Bibliography

DOI http://dx.doi.org/

10.1055/s-0032-1321908

Published online ahead of print:

September 7, 2012

Pharmacopsychiatry 2013;

46: $54-58$

(c) Georg Thieme Verlag KG

Stuttgart · New York

ISSN 0176-3679

Correspondence

M. Deuschle, MD

Central Institute of Mental

Health

68159 Mannheim

Germany

Tel.: + 49/621/17032331

Fax: $+49 / 621 / 17032325$

michael.deuschle@zi-

mannheim.de
Next to evidence demonstrating that stress decreases the expression of brain-derived neurotrophic factor (BDNF) leading to structural damage in limbic neurons, the BDNF-stimulating effect of antidepressants contributed to the formulation of the "neurotrophin hypothesis of depression" $[1,2]$.

In rodents, chronic electroconvulsive treatment or antidepressant treatment enhanced the expression of hippocampal BDNF and prevented damaging effects of stress $[3,4]$. BDNF infusion in the hippocampus produced an antidepressant effect in various behavioral models of depression suggesting BDNF to be involved in the therapeutic action of antidepressants [5]. Most antidepressants, including venlafaxine $[6,7]$ and mirtazapine [8], may increase the hippocampal expression of BDNF, while others did not (fluoxetine $[9,10]$; tranylcypromine, fluoxetine, desipramine [11]; citalopram [12]; escitalopram [13]).

*Both authors contributed equally to this work.
Results: There was a significant "treatment" by "medication" interaction effect on BDNF serum concentrations that indicated a decline of BDNF in venlafaxine-treated patients (7.82 \pm 3.75 $7.18 \pm 5.64 \mathrm{ng} / \mathrm{mL}$ ), while there was an increase in mirtazapine-treated patients $(7.64 \pm 6.23$ $8.50 \pm 5.37 \mathrm{ng} / \mathrm{mL}$ ). There was a trend for a "treatment" by "remission" interaction with a favourable clinical course being related to increasing serum BDNF.

Discussion: Changes in BDNF serum concentrations as a result of antidepressant therapy depend on the antidepressant and potentially on the clinical course.
In line with a recent meta-analysis [14], an epidemiological study $(\mathrm{n}=962)$ found serum BDNF to be low in currently depressed subjects and to be normalized in remission, while antidepressants were differentially related to serum BDNF (St. John's wort > SSRI > venlafaxine > TCA > mirtazapine) [15]. Thus, antidepressants may differ in their ability to induce BDNF. A small case series showed sertraline having early, venlafaxine late and some antidepressants, like escitalopram, no effect on serum BDNF [16]. Negative findings with regard to venlafaxine [17] emerged in other studies, while mirtazapine's effects on serum BDNF have never been studied. Most treatment studies did not specifically consider treatment response as a potential factor for BDNF regulation or studied only treatment responders [18-21], while others found increasing serum BDNF in female responders to antidepressant treatment only [22] or no association with treatment response at all $[17,23]$.

Taken together, the effect of antidepressants on serum BDNF is undisputed, while it is unclear whether all classes of antidepressants affect 
BDNF equally and whether the effect is confined to treatment responders. Therefore, we intended (a) to compare serum BDNF between healthy controls and depressed subjects, (b) to study the effect of antidepressant treatment on serum BDNF, (c) to disentangle the effects of venlafaxine vs. mirtazapine and treatment response on serum BDNF and (d) to test whether serum BDNF is related to platelet numbers or volume.

\section{Material and Methods}

$\nabla$

\section{Patients and healthy controls}

We included adult inpatients with a major depressive episode diagnosed according DSM-IV and a score of at least 18 points on the Hamilton depression rating scale (HDRS, 21 items). There were 41 female (age: $53.2 \pm 17.2$ years; body mass index [BMI]: $26.0 \pm 6.3 \mathrm{~kg} / \mathrm{m}^{2}$; HDRS after wash-out: $23.2 \pm 4.5$ ) and 14 male patients (age: $49.4 \pm 12.9$ years; BMI: $25.2 \pm 4.3 \mathrm{~kg} / \mathrm{m}^{2}$; HDRS after wash-out: $22.1 \pm 3.8$ ). Also, we included 14 healthy controls ( 13 female $/ 1$ male; age: $56.7 \pm 11.6$ years; BMI: $25.1 \pm 4.8 \mathrm{~kg} / \mathrm{m}^{2}$ ). Healthy controls were recruited by advertisement. Screening procedures included a psychiatric interview, physical examination, laboratory analyses and brain imaging (patients only). Exclusion criteria were a lifetime diagnosis of schizophrenia, schizoaffective disorder or bipolar disorder, substance dependence and pre-treatment with venlafaxine, mirtazapine, fluoxetine or long-acting antipsychotics during the current episode. Also, we excluded subjects with incomplete or haemolytic samples or baseline BDNF serum concentrations above mean plus 5 SDs (1 patient: male, 52 years). Semi-standardized diagnostic interviews revealed no current and lifetime axis I disorder, especially affective disorders, in healthy controls. All subjects provided written informed consent and the study was approved by the local ethics committee.

\section{Study design}

Patients were kept off psychiatric medication for a period of at least 6 days (week -1 ), after which they received randomized (pre-defined allocation list), although open label treatment with either venlafaxine (final dosage: $203 \pm 47 \mathrm{mg}$ ) or mirtazapine (final dosage: $46 \pm 9 \mathrm{mg}$ ) in flexible dosages for 4 weeks. With the exception of lorazepam (33/55 patients; mean total dosage $5.1 \pm 8.7 \mathrm{mg}$ ) and zolpidem (11/55 patients; mean total dosage $44.4 \pm 86.4 \mathrm{mg}$ ), no additional psychotropic medication was allowed throughout the study. Compliance during inpatient treatment was assured by ward staff.

Psychopathology was assessed by the treating psychiatrist (MG, BS) once a week by means of the HDRS. Both clinicians were experienced and blind with regard to BDNF measures. However, there was no formal HDRS training. Patients with less than 18 points at the end of the drug-free run-in period or a drop of $\geq 10$ points during that period (week -1) were excluded from the study as responders during washout. Remission was defined as a final HDRS score of $\leq 7$ [24].

\section{Laboratory methods}

On the mornings of day -1 and day 28 blood was drawn, centrifuged $(800 \times \mathrm{g}$ for $15 \mathrm{~min})$ and serum samples stored at $-80^{\circ} \mathrm{C}$ until BDNF concentrations were determined. BDNF serum concentrations were quantified by a modified ELISA (Promega Co., Madison, WI, USA) as described in detail previously $[25,26]$. Endogenous BDNF levels were measured in the rethawed serum samples using commercial ELISA kits according to the manufacturer's instructions (Promega Inc., USA) but adapted to a fluorometric technique. Briefly, microtiter plates (Thermoscientific; microfluor2Black, 96-well, flat-bottom) were coated with $100 \mu \mathrm{L} /$ well of primary monoclonal anti-BDNF antibody diluted 1:1000 in carbonate buffer ( $\mathrm{pH}$ 9.6). After an overnight incubation at $4^{\circ} \mathrm{C}$ the plates were washed once with washing buffer (Tris-buffered saline with $0.05 \% \mathrm{NP}-40$ ). As a blocking step, $200 \mu \mathrm{L}$ of Block \& Sample Buffer $1 \times$ (Promega) were added into each well and incubated for $1 \mathrm{~h}$ in the dark at room temperature. After washing the plates 5 times with washing buffer, $100 \mu \mathrm{L}$ of the samples (diluted 1:200 in Block \& Sample Buffer 1×), recoveries [serum added with a known concentration of hBDNF (Alomone Labs)] and standards were added. The samples were measured in triplicate, the standards in duplicate and the recoveries in monoplicate. After an incubation step of $2 \mathrm{~h}$ in the dark at room temperature, the plates were washed 5 times with washing buffer. $100 \mu \mathrm{L}$ of the secondary anti-BDNF polyclonal antibody (Promega) diluted 1:500 in Block \& Sample Buffer 1× were added into each well, followed by an incubation step of $2 \mathrm{~h}$ in the dark at room temperature. After washing 5 times with washing buffer again, $100 \mu \mathrm{L}$ of anti-chicken IgY alkaline phosphatase conjugate (Abcam) diluted 1:2000 in Block \& Sample Buffer $1 \times$ were added into each well and incubated for $1.5 \mathrm{~h}$ in the dark at room temperature. This incubation is followed by washing 5 times with washing buffer and 2 times with substrate buffer $\left(0.1 \mathrm{M}\right.$ sodium phosphate at $\left.\mathrm{pH} 8.7 ; 1 \mathrm{mM} \mathrm{MgCl}_{2}\right)$. Enzyme reaction was started by adding $50 \mu \mathrm{L}$ AttoPhos Substrate Set (Roche Diagnostics $\mathrm{GmbH}$ ) into each well, incubating over night in the dark in a moist chamber at room temperature. The reaction was stopped by adding $200 \mu \mathrm{L}$ Stop Solution ( $0.15 \mathrm{M}$ glycine; $\mathrm{pH} 10.5$ ) into each well. The emission was measured with a fluorescence photometer (excitation wavelength $485 \mathrm{~nm}$, emission wavelength $538 \mathrm{~nm}$ ). This assay has a detection limit of $0.7 \mathrm{pg} / \mathrm{mL}$ serum BDNF, the coefficients of inter- and intra-assay variation are $34.1 \%$ and $6.7 \%$, respectively [23]. Since the intra-assay variation is much less than the inter-assay variation, the corresponding pre- and post-treatment samples of patients were always measured in the same BDNF assay.

\section{Statistics}

Univariate and analysis of variance with repeated measures (ANOVA-rm) using treatment (pre vs. post), medication (mirtazapine vs. venlafaxine) and outcome (remission vs. nonremission; relative change of HDRS score) as independent variables as well as Pearson's correlations were used as appropriate. Posthoc tests were performed with a 2-tailed significance value set to 0.05 . Data are reported as means \pm standard deviations.

\section{Results}

\section{$\nabla$}

Healthy controls and depressed patients did not differ with regard to age (controls vs. patients: $56.7 \pm 11.6$ vs. $52.2 \pm 16.2$ years, n.s.) or body mass index (controls vs. patients: $25.1 \pm 4.8$ vs. $25.8 \pm 5.8 \mathrm{~kg} / \mathrm{m}^{2}$, n.s.). There was a difference in sex distribution $\left(1 \mathrm{~m} / 14 \mathrm{f}\right.$ vs. $13 \mathrm{~m} / 41 \mathrm{f}, \mathrm{X}^{2}=22.0, \mathrm{p}<0.001$; see $\odot$ Table 1$)$. Healthy controls and depressed patients did not differ in BDNF serum concentrations ( $6.64 \pm 2.11$ vs. $7.29 \pm 4.00 \mathrm{ng} / \mathrm{mL}$, n.s.). Sex and age had no significant effect on BDNF serum concentrations. In depressed patients, severity of depression at baseline as 
Table 1 Clinical characteristics, platelets and serum BDNF in depressed patients being treated with mirtazapine vs. venlafaxine.

\begin{tabular}{|c|c|c|c|c|c|c|}
\hline & \multicolumn{2}{|c|}{ Mirtazapine treatment } & \multicolumn{2}{|c|}{ Venlafaxine treatment } & \multicolumn{2}{|c|}{$\begin{array}{l}\text { Unpaired t-test, } \mathrm{X}^{2} \text {-test, ANOVA repeated } \\
\text { measures }\end{array}$} \\
\hline gender $(f / m)$ & \multicolumn{2}{|l|}{$22 / 7$} & \multicolumn{2}{|l|}{$19 / 8$} & \multicolumn{2}{|l|}{ n.s. } \\
\hline age (years) & \multicolumn{2}{|l|}{$50.5 \pm 18.0$} & \multicolumn{2}{|l|}{$54.1 \pm 13.8$} & \multicolumn{2}{|l|}{ n.s. } \\
\hline age of onset & \multicolumn{2}{|l|}{$42.0 \pm 16.4$} & \multicolumn{2}{|l|}{$42.9 \pm 16.9$} & \multicolumn{2}{|l|}{ n.s. } \\
\hline recurrent/single & \multicolumn{2}{|l|}{$18 / 11$} & \multicolumn{2}{|l|}{$22 / 5$} & \multicolumn{2}{|l|}{$p<0.01$} \\
\hline nr. of episodes & \multicolumn{2}{|l|}{$3.9 \pm 5.9$} & \multicolumn{2}{|l|}{$3.1 \pm 2.6$} & \multicolumn{2}{|l|}{ n.s. } \\
\hline duration episode (weeks) & \multicolumn{2}{|c|}{$15 \pm 12$} & \multicolumn{2}{|c|}{$18 \pm 15$} & \multicolumn{2}{|l|}{ n.s. } \\
\hline \multirow[t]{2}{*}{$\begin{array}{l}\text { pre-treatment (last } 4 \\
\text { weeks) }\end{array}$} & \multicolumn{2}{|c|}{$\begin{array}{l}14 \text { none, } 3 \text { SSRI, } 3 \text { TCA, } 4 \text { other anti- } \\
\text { depressants, } 2 \text { combinations, } 1 \text { mood } \\
\text { stabilizer, } 1 \text { atypical antipsychotic, } 1 \\
\text { unclear }\end{array}$} & \multicolumn{2}{|c|}{$\begin{array}{l}12 \text { none, } 3 \text { SSRI, } 3 \text { TCA, } 1 \text { MAOI, } 2 \\
\text { other antidepressants, } 4 \text { combina- } \\
\text { tions, } 1 \text { mood stabilizer + antide- } \\
\text { pressant, } 1 \text { low potent antipsychotic }\end{array}$} & & \\
\hline & before treatment & after treatment & $\begin{array}{l}\text { before treat- } \\
\text { ment }\end{array}$ & after treatment & effect: "treatment" & $\begin{array}{l}\text { interaction effect: } \\
\text { "treatment" × “medi- } \\
\text { cation" }\end{array}$ \\
\hline HDRS rating & $22.7 \pm 4.2$ & $8.9 \pm 6.0$ & $23.0 \pm 4.5$ & $7.4 \pm 5.3$ & $F_{1,54}=42.1 ; p=0.001$ & n.s. \\
\hline BMI $\left[\mathrm{kg} / \mathrm{m}^{2}\right]$ & $25.2 \pm 6.2$ & $25.6 \pm 6.3$ & $26.4 \pm 4.2$ & $26.3 \pm 4.3$ & n.s. & $F_{1,49}=6.58 ; p=0.02$ \\
\hline BDNF [ng/mL] & $7.64 \pm 6.23$ & $8.50 \pm 5.37$ & $7.82 \pm 3.75$ & $7.18 \pm 5.64$ & n.s. & $F_{1,51}=5.04 ; p=0.029$ \\
\hline platelet number [1 000/mL] & $275 \pm 97$ & $295 \pm 115$ & $273 \pm 81$ & $284 \pm 90$ & $F_{1,31}=4.51 ; p=0.041$ & n.s. \\
\hline platelet volume $[\mathrm{fL}]$ & $8.34 \pm 0.90$ & $8.12 \pm 0.76$ & $8.04 \pm 0.85$ & $8.10 \pm 0.98$ & n.s. & n.s. \\
\hline
\end{tabular}

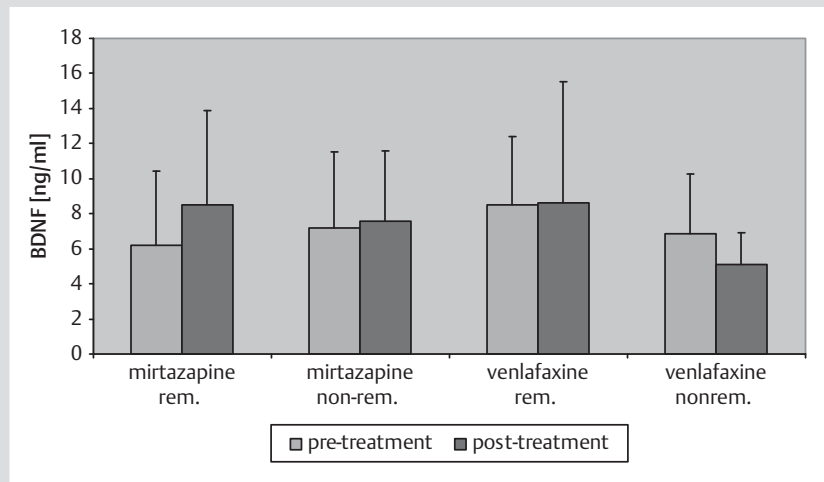

Fig. 1 Serum BDNF before and after treatment with mirtazapine and venlafaxine.

measured by HDRS was not related to BDNF serum concentrations $(r=-0.15$, n.s.).

Before treatment, mirtazapine- and venlafaxine-treated patients did not differ with regard to age ( $50.4 \pm 18.3$ vs. $54.1 \pm 13.8$ years, n.s.) and body mass index $\left(24.4 \pm 5.9\right.$ vs. $27.2 \pm 5.6 \mathrm{~kg} / \mathrm{m}^{2}$, $\mathrm{p}=0.074$ ). Patients were well-matched according to clinical features, except that in the venlafaxine group less patients had major depression, single episode. After treatment, 11/25 mirtazapine- and 14/24 venlafaxine-treated patients were in remission. The final HDRS score was normally distributed (Kolmogorov-Smirnov) with a mean score of $8.18 \pm 5.66$ (range $0-22$ ). There was no difference in total usage of lorazepam between the group treated with mirtazapine $(6.0 \pm 9.1 \mathrm{mg})$ and the group treated with venlafaxine $(5.3 \pm 12.3 \mathrm{mg})$.

ANOVA-rm revealed a significant interaction effect of "treatment" × "medication" (Wilk's lambda $=0.910, \quad \mathrm{~F}_{1,51}=5.04$, $\mathrm{p}=0.029$ ) and a trend effect of borderline significance for a "treatment" $\times$ "outcome" interaction (Wilk's lambda $=0.928$, $\left.\mathrm{F}_{1,51}=3.93, \mathrm{p}=0.053\right)$ on serum BDNF. There was no effect of "treatment" (repeated measures) and no significant "treatment" $\times$ "outcome" $\times$ "medication" interaction. BDNF serum concentrations increased in patients remitting during treatment with mirtazapine $(6.21 \pm 4.22-8.50 \pm 5.40 \mathrm{ng} / \mathrm{mL}$, paired $\mathrm{T}=-2.81$, $\mathrm{p}=0.017)$, but not venlafaxine $(8.50 \pm 3.91-8.61 \pm 6.91 \mathrm{ng} / \mathrm{mL}$, n.s. $)$. In non-remitting patients, there was no change of serum BDNF in mirtazapine-treated patients $(7.20 \pm 4.33-7.55 \pm 4.05 \mathrm{ng} / \mathrm{mL}$, n.s. $)$, while BDNF serum concentrations significantly declined in venlafaxine-treated patients $(6.83 \pm 3.42-5.11 \pm 1.80 \mathrm{ng} / \mathrm{mL}$, paired $\mathrm{T}=2.439, \mathrm{p}=0.035$ ) (see $\odot$ Fig. 1). Controlling for age or sex did not change the findings ( $\odot$ Fig. 1 ). Accordingly, the relative change of serum BDNF $\left(t_{28}-t_{-1} / t_{-1}\right)$ depended on "medication" $\left(\mathrm{F}_{1,51}=11.2, \mathrm{p}<0.001\right)$ and relative change of HDRS rating $\left(\mathrm{F}_{1,51}=4.4, \mathrm{p}=0.04\right)$.

Platelet number at the time of sampling for BDNF (available in 37 patients) slightly increased over time (pre vs. post: $270.351 \pm$ 84.280 vs. $284.838 \pm 103.523 \mathrm{n} / \mathrm{mL}$, Wilk's lambda $=0.880, \mathrm{~F}_{1,31}=$ 4.51, $\mathrm{p}=0.041$ ), while ANOVA-rm did not reveal significant effects of "treatment" $\times$ "medication" or "treatment" $\times$ "outcome" interactions (all $\mathrm{F}<0.6$, n.s.). Platelet volume (available in 37 patients) did not change during treatment (pre vs. post: $8.0 \pm 0.86$ vs. $8.1 \pm 0.89$ $\mathrm{fl}, \mathrm{n} . \mathrm{s}$.) and there was no effect of "medication" or "outcome" (all $\mathrm{F}<1.7$, n.s.). Neither platelet number nor volume at baseline were related to BDNF serum concentrations $(r=0.195, r=0.028$; both n.s.).

\section{Discussion}

In our study, serum BDNF did not differ between depressed patients and healthy controls and, in contrast to earlier findings [27], within the group of patients serum BDNF was not related to severity of depression. Of course, we cannot exclude that this negative finding is due to the small healthy control sample size, the moderate severity of depression or carry-over effects of antidepressant pre-treatment.

While the small sample size and uneven gender distribution may have not allowed us to adequately assess the effects of diagnosis and gender, the sample size was considered sufficient to analyze treatment effects. During antidepressant treatment, the change of serum BDNF depended on medication (mirtazapine $>$ venlafaxine) and clinical outcome (remission $>$ non-remission). Antidepressants are thought to up-regulate the expression of cerebral BDNF and its receptor trkB [28] and to increase adult 
neurogenesis $[29,30]$ which might be at the core of antidepressant activity. Recent studies in animal models of depression demonstrated that antidepressant classes differ in their potential to induce hippocampal BDNF mRNA changes [9-13]. While there is evidence that different classes of antidepressants differentially influence hypothalamus-pituitary-adrenal (HPA) axis parameters in humans [31,32], there is only limited information on changes in BDNF serum concentrations after administration of different antidepressants. Both, cross-sectional epidemiological [15] as well as longitudinal studies support the hypothesis that antidepressants have heterogeneous effects on serum BDNF $[16,17,23]$. Only few studies considered response to treatment to play a role in antidepressants' effects on serum BDNF. Our data support the notion that both, choice of medication and, with borderline significance, treatment response are relevant for the effects on serum BDNF. Interestingly, the effect of outcome differed between both drugs. We found increasing serum BDNF only in mirtazapine remitters, no change in mirtazapine nonremitters and venlafaxine remitters, but a decline of serum BDNF in venlafaxine non-remitters. To the best of our knowledge, this is the first report of declining serum BDNF during antidepressant treatment with a specific drug. Of course, most of our patients were not drug-naïve. Thus, declining serum BDNF concentrations during unsuccessful treatment with venlafaxine may be due to a weaker effect of venlafaxine on serum BDNF when compared to pre-treatment.

The source and significance of serum BDNF is not fully understood. Serum BDNF may be independent from platelet reactivity [33] and there is evidence that cerebral and peripheral BDNF are related $[4,34]$. BDNF has been shown to cross the blood-brain barrier by a high-capacity, saturable transport system $[35,36]$. However, it remains unclear whether serum BDNF reflects or contributes to brain BDNF.

A mirtazapine-mediated increase of BDNF seems feasible as also animal studies suggest an increase of BDNF during chronic mirtazapine treatment, at least in the hippocampus and the prefrontal cortex of rats $[8,36]$.

Differential effects of mirtazapine [37], which decreases platelet activity and venlafaxine [38], which increases platelet activity, might explain our current observation. In this context we might miss the BDNF redistribution between platelets and plasma, which has been described during SSRI treatment [39] as we only studied serum concentrations.

In contrast to most recent studies, we did not find depressed patients and males to have lower BDNF serum concentrations when compared to controls and females [40], respectively. This might be due to small sample size and uneven gender distribution. Apart from the obvious limitation due to the small sample size, our results should be interpreted with caution in view of the short drug-free interval before the start of the study, short duration of the antidepressant trial, the small group of healthy controls as well as the unusually high rate of patients being in remission after inpatient antidepressant treatment. These limitations may limit generalizability of our findings. However, this is the first randomized study comparing the effects of 2 antidepressants on serum BDNF and considering the clinical course as a potential factor. In humans, a polymorphism in the BDNF gene has been associated with depression-related personality traits, i.e., neuroticism [41]. Regrettably, the BDNF genotype was not analyzed, but could have contributed to both the negative finding with regard to diagnosis as well as the treatment effects. A subgroup of patients, but not controls, were given lorazepam and zolpidem in low dosages. So far, it is assumed that benzodiazepines do not affect BDNF levels [42], except in the case of withdrawal or catatonia.

Taken together, our data give evidence to the assumption that antidepressants may have different effects on serum BDNF. The clinical course should be considered in future studies.

\section{Acknowledgements \\ $\nabla$}

The authors thank Silvia Saft, Susanne Laubender and Angela Heuer for technical assistance. The study was supported by a grant from the Deutsche Forschungsgemeinschaft (DFG De 660/7-1).

\section{Conflict of Interest \\ $\nabla$}

Yes: Dr. Deuschle has received speaker fees from Otsuka and Bristol Myers Squibb.

\section{References}

1 Duman RS, Monteggia LM. A neurotrophic model for stress-related mood disorders. Biol Psychiatry 2006; 59: 1116-1127

2 Castrén E, Rantamäki T. Role of brain-derived neurotrophic factor in the aetiology of depression: implications for antidepressant treatment. CNS Drugs 2010; 24: 1-7

3 Nibuya M, Morinobu S, Duman R. Regulation of BDNF and TrkB messenger RNA in rat brain by chronic electroconvulsive seizure and antidepressant drug treatments. J Neuroscience 1995; 15: 7539-7547

4 Sartorius A, Hellweg R, Litzke J et al. Correlations and discrepancies between serum and brain tissue levels of neurotrophins after electroconvulsive treatments in rats. Pharmacopsychiatry 2009; 42: 270-276

5 Shirayama Y, Chen ACH, Nakagawa S. Brain-derived neurotrophic factor produces antidepressant effects in behavioural models of depression. J Neuroscience 2002; 22: 3251-3261

6 Cooke JD, Grover LM, Spangler PR. Venlafaxine treatment stimulates expression of BDNF protein in frontal cortex and inhibits long-term potentiation in hippocampus. Neuroscience 2009; 162: 1411-1419

$7 \mathrm{Xu} \mathrm{HY}$, Chen Z, He J et al. Synergistic effects of quetiapine and venlafaxine in preventing the chronic restraint stress-induced decrease in cell proliferation and BDNF expression in rat hippocampus. Hippocampus 2006; 16: 551-559

8 Rogoz Z, Skuza G, Legutko B. Repeated treatment with mirtazapine induces brain-derived neurotrophic factor gene expression in rats. J Physiol Pharmacol 2005; 56: 661-671

9 Dias BG, Banerjee SB, Duman RS et al. Differential regulation of brain derived neurotrophic factor transcripts by antidepressant treatments in the adult rat brain. Neuropharmacol 2003; 45: 553-563

10 Russo-Neustadt AA, Alejandre H, Garcia C et al. Hippocampal brainderived neurotrophic factor expression following treatment with reboxetine, citalopram, and physical exercise. Neuropsychopharmacology 2004; 29: 2189-2199

11 Altar CA, Whitehead RE, Chen RY et al. Effects of electroconvulsive seizures and antidepressant drugs on brain-derived neurotrophic factor protein in rat brain. Biol Psychiatry 2003; 54: 703-709

12 Jacobsen JPR, Mork A. The effect of citalopram, desipramine, electroconvulsive seizures and lithium on brain-derived neurotrophic factor mRNA and protein expression in the rat brain and correlation to 5-HT and 5-HIAA levels. Brain Res 2004; 1024: 183-192

13 Schulte-Herbrüggen $O$, Fuchs E, Abumaria $N$ et al. Effects of escitalopram on the regulation of brain-derived neurotrophic factor and nerve growth factor protein levels in a rat model of chronic stress. J Neurosci Res 2009; 87: 2551-2560

14 Sen S, Duman R, Sanacora G. Serum brain-derived neurotrophic factor, depression and antidepressant medications: meta-analysis and implications. Biol Psychiatry 2008; 64: 527-532

15 Molendijk ML, Bus BAA, Spinhoven $P$ et al. Serum levels of brainderived neurotrophic factor in major depressive disorder: state-trait issues, clinical features and pharmacological treatment. Mol Psychiatry $2011 ; 16: 1088-1095$ 
16 Matrisciano F, Bonaccorso S, Ricciardi A et al. Changes in BDNF serum levels in patients with major depression disorder after 6 months treatment with sertraline, escitalopram or venlafaxine. J Psychiat Res 2008; 43: 247-254

17 Basterzi AD, Yazici K, Aslan E et al. Effects of fluoxetine and venlafaxine on serum brain derived neurotrophic factor levels in depressed patients. Prog Neuro Psychopharmacol Biol Psych 2009; 33: 281-285

18 Aydemir C, Yalcin ES, Aksaray S et al. Brain-derived neurotrophic factor (BDNF) changes in serum of depressed women. Prog Neuropsychopharmacol Biol Psychiatry 2006; 30: 1256

19 Gervasoni N, Aubry JM, Bondolfi G et al. Partial normalization of serum brain-derived neurotrophic factor in remitted patients after a major depressive episode. Neuropsychobiology 2005; 51: 234-238

20 Gonul AS, Akdeniz F, Taneli $F$ et al. Effect of treatment on serum brainderived neurotrophic factor levels in depressed patients. Eur Arch Psych Clin Neurosci 2005; 255: 381-386

21 Piccinni A, Marazziti D, Catena $M$ et al. Plasma and serum brainderived neurotrophic factor (BDNF) in depressed patients during 1 year of antidepressant treatments. J Affect Disord 2008; 105: 279-283

22 Huang TL, Lee CT, Liu YL. Serum brain-derived neurotrophic factor levels in patients with major depression: effects of antidepressants. J Psychiatr Res 2007; 42: 521-525

23 Hellweg R, Ziegenhorn A, Heuser I et al. Serum concentrations of nerve growth factor and brain-derived neurotrophic factor in depressed patients before and after antidepressant treatment. Pharmacopsychiatry 2008; 41: 66-71

24 Möller HJ. Outcomes in major depressive disorder: the evolving concept of remission and its implications for treatment. W J Biol Psychiatry 2008; 9: 102-114

25 Hellweg $R$, Lohmann $P$, Huber $R$ et al. Spatial navigation in complex and radial mazes in APP23 animals and neurotrophin signalling as a biological marker of early impairment. Learn Mem 2006; 13: 63-71

26 Ziegenhorn AA, Schulte-Herbrüggen 0 , Danker-Hopfe $H$ et al. Serum neurotrophins - a study on the time course and influencing factors in a large old age sample. Neurobiol Aging 2006; 28: 1436-1445

27 Satomura E, Baba H, Nakano $Y$ et al. Correlations between brainderived neurotrophic factor and clinical symptoms in medicated patients with major depression. J Affect Disord 2011; 135: 232-325

28 Russo-Neustadt A, Beard RC, Cotman CW. Exercise, antidepressant medications, and enhanced brain derived neurotrophic factor expression. Neuropsychopharmacology 1999; 21: 679-682

29 Duman R. Depression: a case of neuronal life and death? Biol Psychiatry 2004 ; 56 : $140-145$
30 Malberg JE, Eisch AJ, Nestler EJ et al. Chronic antidepressant treatment increases neurogenesis in adult rat hippocampus. J Neurosci 2000; 20: $9104-9110$

31 Deuschle M, Hamann B, Meichel C et al. Antidepressive treatment with amitriptyline and paroxetine: effects on saliva cortisol concentrations. J Clin Psychopharmacol 2003; 23: 201-205

32 Scharnholz B, Weber-Hamann B, Lederbogen $F$ et al. Antidepressant treatment with mirtazapine, but not venlafaxine, lowers cortisol concentrations in saliva: a randomised open trial. Psychiatry Res 2010; 177: 109-113

33 Karege F, Bondolfi G, Gervasoni $N$ et al. Low brain-derived neurotrophic factor (BDNF) levels in serum of depressed patients probably results from lowered platelet BDNF release unrelated to platelet reactivity. Biol Psychiatry 2005; 57: 1068-1072

34 Karege F, Perret G, Bondolfi $G$ et al. Decreased serum brain-derived neurotrophic factor levels in major depressed patients. Psychiatry Res 2002; 109: 143-148

35 Pan W, Banks WA, Fasold MB et al. Transport of brain-derived neurotrophic factor across the blood-brain barrier. Neuropharmacology 1998; 37: 1553-1561

36 Zhang Y, Gu F, Chen J et al. Chronic antidepressant administration alleviates frontal and hippocampal BDNF deficits in CUMS rat. Brain Res 2010; 1366: 141-148

37 Schins A, Hamulyák $K$, Scharpé $S$ et al. Whole blood serotonin and platelet activation in depressed post-myocardial infarction patients. Life Sci 2004; 76: 637-650

38 Tharmapathy $P$, Selheim $F$, Odegaard $K$ et al. Venlafaxine treatment stimulates blood platelet activity. J Clin Psychopharmacol 2000; 20: 589-590

39 Serra-Millàs M, López-Vílchez I, Navarro $V$ et al. Changes in plasma and platelet BDNF levels induced by S-citalopram in major depression. Psychopharmacology 2011; 216: 1-8

40 Trajkovska $V$, Marcussen $A B$, Vinberg $M$ et al. Measurement of brainderived neurotrophic factor: methodological aspects and demographic data. Brain Res Bull 2007; 73: 143-149

41 Sen S, Nesse RM, Stoltenberg SF et al. A BDNF coding variant is associated with the NEO personality inventory domain neuroticism, a risk factor for depression. Neuropsychopharmacology 2003; 28: 397-401

42 Balu DT, Hoshaw BA, Malberg JE et al. Differential regulation of central BDNF protein levels by antidepressants and non-antidepressant drug treatments. Brain Res 2008; 1211: 37-43 